\title{
Markov-Switching Stochastic Trends and Economic
}

\author{
Fluctuations
}

\author{
Maximo Camacho* \\ Departamento de Metodos Cuantitativos. \\ Universidad de Murcia, 30100, Murcia, Spain. \\ email: mcamacho@um.es
}

\begin{abstract}
I investigate cointegrating relationships such that, even though the long-run attractors are assumed to be linear, the dynamics of the equilibrium errors depends on the business cycle. I postulate a Markov-switching common stochastic trends model to study both the short-run responses to permanent shocks and the effects of recessions in the long-run growth. I apply these findings to explore the short-run and long-run asymmetric relationships among output, consumption and investment.
\end{abstract}

JEL classifications: C32, C51, E32.

Key words: asymmetric adjustment, nonlinear error correction, Markov-switching.

\footnotetext{
${ }^{*}$ The author is indebted to Gabriel Perez-Quiros, his thesis advisor, for many stimulating conversations, and to the Spanish Ministry of Education for financial support (CICYT SEC2001-0855). Comments of A. Beyaert, G. Camba, H. van Dijk, I. Sancho, J. Gonzalo, J. Rust, N. Vriend, two anonymous referees, and seminar participants of the CEF 2002 conference were also very helpful. Data and software (written in GAUSS) used in this paper can be obtained at www.um.es/econometria/Maximo.
} 


\section{Introduction}

Many nonstationary variables, even though may behave separately in the short-run, present a closely related long-run pattern. Engle and Ganger (1987) describe these variables as being in a long-run equilibrium, in the sense that a linear combination of their levels behaves as an attractor. Thus, while most of the time the system is out of equilibrium, economic forces such as market mechanisms or government interventions, tend to correct these equilibrium errors. One drawback of the Engle-Granger approach is that it implicitly imposes symmetry in the dynamics of the equilibrium errors. This leads recent studies to consider that market mechanisms and government interventions may also lead to asymmetric dynamics of the equilibrium errors. On the one hand, Caballero and Hammour (1994) argue, within a creative-destruction framework, that there are market mechanisms moving the economy from a deep recession into the attractor more aggressively that it falls from expansions. On the other hand, the asymmetric adjustment may also be due to policy interventions. During recessions, policy authorities usually react more drastically against the adverse economic situation, accelerating the convergence toward the attractor. Even though we assume similar initiative for mitigating the effects of expansions and recessions, many authors have postulated the existence of a convex aggregate supply curve implying that monetary policy would have stronger effects within recessions. Garcia and Schaller (2002) have found empirical evidence supporting this view.

The examination of this nonlinear adjustment mechanism has been one important development in recent time-series literature. The natural way of dealing with this problem has been by incorporating nonlinear econometric techniques to both the vector error correc- 
tion model of Engle and Ganger (1987) and the common stochastic trends representation of Stock and Watson (1988a). Within the former, examples are the Markov-switching approach of Krolzig (1997, 1999), Krolzig and Toro (1999), Psaradakis et al. (2001), Krolzig et al. (2002) and Francis and Owyang (2003), the threshold approach of Balke and Fomby (1997) and Enders and Siklos (2001), the bilinear model approach of Peel and Davidson (1998), and the smooth transition regression approach of van Dijk and Franses (2000), and Rothman et al. (2001). Within the latter, examples are the dynamic factor regime switching model of Kim and Piger (2002), and the Markov-switching bayesian approach of Paap and van Dijk (2003).

In this paper, I contribute to the growing literature on nonlinear long-run adjustment by developing an alternative representation to the Markov-switching vector error correction model stated in Krolzig (1997, 1999): the Markov-switching common trends representation. For this attempt, I incorporate the asymmetric adjustment to the longrun equilibrium by assuming that the dynamics of the equilibrium errors is subject to regime switching business-cycle pattern. I show that this is closely related to a Markovswitching extension of the common stochastic trends representation developed by Stock and Watson (1988a). This leads to a decomposition of the series into permanent and transitory components that behave asymmetrically within the business cycles. In line with the dynamic factor model of Kim and Piger (2002), my specification captures two types of business-cycle asymmetries. According to the asymmetry advocated by Hamilton (1989), the long-run component is viewed as combinations of random walks whose rates of growth are state-dependent. According to the asymmetry suggested by Friedman (1993), the short-run component presents Markov-switching coefficients and exhibits asymmetric 
deviations of the variables from the trend component.

I apply these findings to examine the short-run and long-run relationships among output, consumption and investment and compare my results with those of the linear approach of King, Plosser, Stock and Watson (1991), henceforth KPSW. This empirical analysis leads to the following interesting results. First, I find empirical evidence in favor of the claim that the equilibrium errors dynamics exhibits business-cycle asymmetries. Second, the estimated Markov-switching common trends representation presents lower insample one-step ahead forecast mean squared error than the linear approach. Several tests confirm the superior predicting accuracy of the nonlinear model. Third, I find that the estimated model may help to characterize the US business cycle features. In particular, I show that the estimated probability that the economy is contracting strongly corresponds to the 20th century NBER recessionary dates. This allows me to consider the date of the through of the first new century's recession, that has not been officially announced by the NBER yet. According to Chauvet (2002), my model indicates that this recession ended in the first quarter of 2002. Fourth, even though I consider a nonlinear specification, my conclusions about the effects of permanent shocks to business cycles fluctuations are comparable to those of KPSW. Finally, in line with Kim et al. (2002) but in contrast to Kim and Piger (2002), even though I consider asymmetries with both permanent and transitory effects, I find that the trend growth rate falls during recessions and hence, that there are permanent decreases in the trend of the series from their position before the recession began. In addition, I obtain that the consequence for the long-run level of the trend is a $1.68 \%$ drop in this trend, that is roughly the half of the value obtained by Hamilton (1989). Following the Kim and Piger (2002) conclusions, this difference may be 
due to the lack of a mechanism to capture transitory types of asymmetry in the Hamilton's model.

I organize the paper as follows. Section 2 provides statistical relationships that link the concepts of asymmetric equilibrium errors and common stochastic trends. Section 3 develops a framework for estimating the current responses to preceding shocks in a context of business cycles asymmetries. Section 4 applies this methodology to investigate the asymmetries in the equilibrium errors dynamics and the long-run effects of business cycle fluctuations. Concluding remarks appear in the last section.

\section{Markov-switching equilibrium errors and common stochas- tic trends}

In a context of cointegrated variables, this section examines the dynamics of equilibrium errors that may depend on the phase of the business cycle. That is, in line with Engle and Granger (1987), I consider a set of $n$ nonstationary variables $x_{t}$ generating $r$ stationary combinations $z_{t}=\beta^{\prime} x_{t}$, with $\beta$ being the $(n \times r)$ cointegrating matrix. In contrast to these authors, I postulate that the equilibrium errors may follow the Markov-Switching Vector Autoregressive (MS-VAR) model:

$$
z_{t}=m_{s_{t}}+A_{s_{t}}(L) z_{t-1}+e_{t}
$$

where $m_{s_{t}}$ is the vector of Markov-switching intercepts, $A_{s_{t}}(L)=\left(A_{s_{t}}^{1}+\ldots+A_{s_{t}}^{p} L^{p-1}\right)$ and $e_{t} \mid s_{t} \sim N(0, V)$. To complete the statistical specification, it is standard to assume that these varying parameters depend upon an unobservable state variable $s_{t}$ that evolves according to an irreducible $q$-state Markov process. This is defined by the transition 
probabilities

$$
p\left(s_{t}=j \mid s_{t-1}=i, s_{t-2}=k, \ldots, \chi_{t-1}\right)=p\left(s_{t}=j \mid s_{t-1}=i\right)=p_{i j},
$$

where $i, j=1,2, \ldots, q$, and $\chi_{t}=\left(z_{t},, z_{t-1}, \ldots.\right)$. In addition, it is convenient to collect them in the $(q \times q)$ transition matrix $P$, whose columns sum to unity. Finally, Yao (2001) and Francq and Zakoïan (2001) show that a sufficient condition for second-order stationarity of $z_{t}$ is that the spectral radius of the matrix

$$
\mho=\left[\begin{array}{ccc}
p_{11}\left(A_{1} \otimes A_{1}\right) & \cdots & p_{q 1}\left(A_{1} \otimes A_{1}\right) \\
p_{12}\left(A_{2} \otimes A_{2}\right) & \cdots & p_{q 2}\left(A_{1} \otimes A_{1}\right) \\
\vdots & \cdots & \vdots \\
p_{1 q}\left(A_{q} \otimes A_{q}\right) & \cdots & p_{q q}\left(A_{q} \otimes A_{q}\right)
\end{array}\right] \text {, with } A_{j}=\left[\begin{array}{ccccc}
A_{j}^{1} & A_{j}^{2} & \cdots & A_{j}^{p-1} & A_{j}^{p} \\
I_{n} & 0 & \cdots & 0 & 0 \\
\vdots & \vdots & \cdots & \vdots & \vdots \\
0 & 0 & \cdots & I_{n} & 0
\end{array}\right]
$$

be less than one. ${ }^{1}$

As shown in Appendix A, the asymmetric dynamics of the equilibrium errors leads to the Markov-Switching Vector Error-Correction Model (MS-VECM):

$$
\Delta x_{t}=\mu_{s_{t}}+\alpha_{s_{t}} z_{t-1}+\pi_{s_{t}}(L) \Delta x_{t-1}+\epsilon_{t},
$$

where $\pi_{s_{t}}(L)=\left(\pi_{s_{t}}^{1}+\ldots+\pi_{s_{t}}^{p} L^{p-1}\right)$, and $\epsilon_{t} \mid s_{t} \sim N(0, \Sigma)$. Note that, whereas I initially consider a state-independent long-run attractor (represented by the matrix $\beta$ ), the nonlinear dynamics of the equilibrium errors cause that both the strength with which the equilibrium errors are corrected (measured by the matrix $\alpha_{s_{t}}$ ) and the short-run dynamics

\footnotetext{
${ }^{1}$ From now on, I will refer to the term stationary equilibrium errors in the sense of the second-order stationarity of Yao (2001) and Francq and Zakoïan (2001).
} 
of the endogenous variables (measured by the matrices $\pi_{s_{t}}^{i}$ ) vary across regimes. ${ }^{2}$

The cointegrated process $x_{t}$ has an alternative representation in terms of a reduced number of common nonlinear stochastic trends. To see this, I state in Appendix B that the stationary change in $x_{t}$ will have the switching moving average representation

$$
\Delta x_{t}=\delta_{s_{t}}+C_{s_{t \downarrow}}(L) \epsilon_{t}
$$

where $\delta_{s_{t}}$ is the conditional mean of $\Delta x_{t}$, and $C_{s_{t \downarrow}}(L)=\left(I+C_{s_{t}}^{1} L+C_{s_{t}, s_{t-1}}^{2} L^{2}+C_{s_{t}, s_{t-2}}^{3} L^{3}+\right.$ ...). What I mean with $C_{s_{t \downarrow}}(L)$ is that parameters in $C(L)$ depend not only on $s_{t}$ but also on $s_{t-1}, s_{t-2}, \ldots$, and what I mean with $C_{s_{t}, s_{t-(j-1)}}^{j}$ is that the matrix $C^{j}$ depends on the sequence of states $s_{t}, s_{t-1}, \ldots, s_{t-(j-1)}$. In addition, I show in Appendix $\mathrm{C}$ that the moving average polynomial $C_{s_{t \downarrow}}(L)$ can always be expressed as $C(1)+(1-L) C_{s_{t \downarrow}}^{*}(L)$, where $C(1)$ refers to $\left(I+C^{1}+C^{2}+\ldots\right)$, with $C^{j}=\sum_{i_{0}=1}^{q} \ldots \sum_{i_{(j-1)}=1}^{q} P\left(s_{t}=i_{0}, \ldots, s_{t-(j-1)}=\right.$ $\left.i_{j-1}\right) C_{s_{t}, s_{t-(j-1)}}^{j}$, and where $C_{s_{t}, s_{t-(j-1)}}^{* j}=-C(1)+I+C_{s_{t-(j-1)}}^{1}+C_{s_{t-(j-2)}, s_{t-(j-1)}}^{2}+\ldots+$ $C_{s_{t}, s_{t-(j-1)}}^{j}$. Thus, substituting recursively and assuming $\epsilon_{0}=0$, it is easy to see that the moving average expression becomes

$$
x_{t}=x_{0}+\sum_{j=1}^{t} \delta_{s_{j}}+C(1) \sum_{j=1}^{t} \epsilon_{j}+C_{s_{t \downarrow}}^{*}(L) \epsilon_{t} .
$$

Stock and Watson (1988a) suggest that, since the equilibrium errors are stationary by assumption, it should be true that $\beta^{\prime} C(1)=0$, and $\beta^{\prime} \delta_{s_{j}}=0$ for all $s_{j}=1, \ldots, q$. This implies that each $\delta_{s_{j}}$ lies in the column space of $C(1)$ and therefore can be written as $\delta_{s_{j}}=C(1) \rho_{s_{j}}$, where $\rho_{s_{j}}$ is an $(n \times 1)$ vector. Thus, since cointegration implies that $\operatorname{rank}[C(1)]=k=n-r$, there is a $(n \times r)$ matrix $\Gamma_{r}^{-1}$ such that $C(1) \Gamma_{r}^{-1}=0$ for all $t$.

\footnotetext{
${ }^{2}$ See Krolzig (1997, 1999), Krolzig and Toro (1999), Psaradakis et al. (2001), and Krolzig et al. (2002) for comparable proposals.
} 
Define the $(n \times k)$ matrix $\Upsilon=C(1) \Gamma_{k}^{-1}$ such that the $k$ columns of $\Gamma_{k}^{-1}$ are orthogonal to the columns of $\Gamma_{r}^{-1}$. This means that $C(1) \Gamma^{-1}=\Upsilon S_{k}$, where $\Gamma^{-1}=\left(\Gamma_{k}^{-1} \Gamma_{r}^{-1}\right)$ and $S_{k}$ is the $(k \times n)$ selection matrix $\left[I_{k} 0_{k \times r}\right]$.

Using these properties, expression (6) may be transformed into:

$$
x_{t}=x_{0}+\Upsilon\left\{S_{k} \Gamma \sum_{j=1}^{t}\left(\rho_{s_{j}}+\epsilon_{j}\right)\right\}+C_{s_{t \downarrow}}^{*}(L) \epsilon_{t} .
$$

To interpret the expression in curly brackets, I follow Granger et al. (1997) to introduce the notion of nonlinear stochastic trends. Specifically, I consider a wider class of trendgenerating $k$ dimensional vector $\tau_{t}$ of random walks with switching drift $\vartheta_{s_{t}}$ and white noise innovations $\varphi_{t}$, such that:

$$
\tau_{t}=\vartheta_{s_{t}}+\tau_{t-1}+\varphi_{t}=\sum_{j=1}^{t}\left(\vartheta_{s_{j}}+\varphi_{j}\right) .
$$

The standard literature usually assumes that the common trend follows a random walk processes with drift that is decomposed into the sum of a linearly deterministic trend plus the sum of persistent errors. However, in my nonlinear context, the dynamics of the variables is state-dependent, which seems to be associated with trends whose "deterministic" growth is not constant along time but rather shifting among regimes.

A trivial verification shows that the expression in braces appearing in (7) can be seen as the switching common stochastic trends, where $\vartheta_{s_{j}}=S_{k} \Gamma \rho_{s_{j}}$, and $\varphi_{j}=S_{k} \Gamma \epsilon_{j}$. This leads to the Markov-Switching Common Trends Model (MS-CTM), that is an extension of the Stock and Watson (1988a) common trend representation:

$$
x_{t}=x_{0}+\Upsilon \tau_{t}+C_{s_{t \downarrow}}^{*}(L) \epsilon_{t},
$$

with $\Upsilon \tau_{t}$ and $C_{s_{t \downarrow}}^{*}(L) \epsilon_{t}$ representing the permanent and transitory components, both 
depending on the sequence of the states. In line with Kim and Piger (2002), when the sequence of states refers to the business cycle phases, this expression allows for two different types of business cycle asymmetries. First, this allows for the Hamilton's type of asymmetry (that is related to permnent effects of recessions) by assuming the regime-dependence of the trends growth rates. Second, this allows for the Friedman's type of asymmetry (that is related to transitory effects of recessions) by assuming the regime-dependence of the transitory component. Consequently, this expression admits the possibility that severe recessions may cause not only temporary deviations from the trends but, in addition, a deterioration in the long-run growth.

\section{Propagation of shocks}

In this nonlinear context, the analysis of the dynamic responses is not straightforward for

several reasons. First, even though the moving average matrices $C_{s_{t}, s_{t-(h-1)}}^{h}$ and the sequence of states were known with certainty, they do not identify the reaction to exogenous shocks, due to the presence of correlations among the statistical errors. One of the mayor contributions in KPSW is to realize that an intuitive way to identify the system is to look for the matrix $\Gamma$ stated in Section 2. This relates structural-form and reduced-form responses as long as the relation $R_{s_{t \downarrow}}(L)=C_{s_{t \downarrow}}(L) \Gamma^{-1}$ holds. Hence, under the assumption that $R_{s_{t \downarrow}}(1)=(\Upsilon, 0)$, shocks that occur at time $t-h$, with $h$ large enough, may be decomposed into permanent-effect shocks (first $k$ shocks) and transitory-effect shocks (last $r$ shocks). On the one hand, KPSW show that the effects of permanent shocks may be approximated by the $(k \times n)$ matrix $\Gamma_{k}=\left(\Upsilon^{\prime} \Upsilon\right)^{-1} \Upsilon^{\prime} C(1)$. Specifically, these au- 
thors suggest that $\Upsilon$ may be obtained by imposing identifying restrictions on the system $\Upsilon \Upsilon^{\prime}=C(1) \Sigma C(1)$, with $\beta^{\prime} \Upsilon=0$. On the other hand, to examine the dynamic effects of the transitory shocks, I refer the reader to the linear approach of Mellander et al. (1992), and Gonzalo and Ng (2001), and the nonlinear works of Camacho (2001), and Krolzig et al. (2002).

Second, the nonlinear nature of my approach implies the history dependence of the responses as described in Koop et al. (1996). That is, given the information up to time $t$, any matrix $R_{s_{t}, s_{t-(h-1)}}^{h}$, collecting the reactions of the endogenous variables at time $t$ to one standard deviation structural shocks at $t-h$, depends on the sequence of unknown states. To estimate these backward-looking responses, I use the approach of Balke and Fomby (1997) and Krolzig (1997, 1999), who suggest a two-stage procedure to estimate the parameters of cointegrated nonlinear models. In the first stage, they suggest to determine the cointegration rank and to deliver an estimation on the cointegrating matrix $\beta$ using the standard Johansen's approach. However, Coakley and Fuertes (2001) have recently documented that the Johansen's method may fail to detect cointegration due to misspecification problems when the true nature of the adjustment process is nonlinear. In this case, these authors suggest the use of the nonparametric cointegration analysis advocated by Bierens (1997) whose results are independent of the data-generating process due to the nonparametric nature of this approach. ${ }^{3}$ In the second stage, the remaining parameters of the MS-CTM specification are estimated with the methods developed for Markov-switching models. For this attempt, I extend to the Markov-switching context

\footnotetext{
${ }^{3}$ The Bierens' approach is based on a nonparametric generalized eigenvalue problem in the same spirit as the Johansen's method.
} 
the method proposed by Warne (1993), who uses an intermediate restricted model to obtain the estimates of $C(1)$ and $\Sigma$. That is, let $y_{t}$ be the stationary transformation of the endogenous variables $\left(\beta^{\dagger}(1-L), \beta\right)^{\prime} x_{t}$. I estimate the so-called Markov-Switching Restricted VAR (MS-RVAR) model

$$
y_{t}=\mu_{s_{t}}^{*}+B_{s_{t}}(L) y_{t-1}+\epsilon_{t}^{*}
$$

which comes from an appropriate manipulation of MS-VECM, with $B_{s_{t}}(L)=B_{s_{t}}^{1}+\ldots+$ $B_{s t}^{p} L^{p-1}$ and $\epsilon_{t}^{*} \mid s_{t} \sim N(0, \Omega)$. This allows me to obtain the appropriate estimates of $B_{s_{t}}(L), \Omega$, and $P$, and to propose, as Appendix B shows, the moving average representation $y_{t}=\varsigma_{s_{t}}+F_{s_{t \downarrow}}(L) \epsilon_{t}^{*}$, with $\varsigma_{s_{t}}$ being the conditional mean of $y_{t}$, and $F_{s_{t \downarrow}}(L)=\left(I+F_{s_{t}}^{1} L+\right.$ $\left.F_{s_{t}, s_{t-1}}^{2} L^{2}+F_{s_{t}, s_{t-2}}^{3} L^{3}+\ldots\right)$. In Appendix D, I follow the linear approach of Warne (1993) to suggest a way to estimate the moving average parameters $F^{j}$, and an iterative method to calculate the backward-looking responses as:

$$
R^{j}=\sum_{i_{0}=1}^{q} \ldots \sum_{i_{(j-1)}=1}^{q} P\left(s_{t}=i_{0}, \ldots, s_{t-(j-1)}=i_{j-1}\right) R_{s_{t}, s_{t-(j-1)}}^{j}
$$

These matrices describe the estimates of the current responses to previous structural shocks as the weighted average of the estimated responses in each state, where the weights are the estimated probabilities of being in each of these states. The backward-looking impulse responses may be related to alternative approaches to deal with impulse responses in the context of Markov-switching suggested in the literature. Ehrmann (2000), Ehrmann et al. (2001, 2003), and Krolzig et al. (2002) compute how fundamental disturbances affect the variables in the model dependent on the Markov-regime. Their regime-dependent responses have the appeal that, conditional on a given regime, present the standard form 
of traditional linear responses and allow for a simple analysis of asymmetries in the responses. ${ }^{4}$ However, as Ehrmann et al. (2003) point out, the validity of regime conditioning depends on the horizon of the impulse response and the expected duration of the regime. This leads me to consider the alternative backward-looking responses to examine the estimated effect of shocks hitting the economy with a lag of 25 quarters as in KPSW. ${ }^{5}$ In addition, one can obtain the backward-looking responses for the levels of the variables by just adding the matrices $R^{j}$, and the backward-looking variance decomposition by using standard manipulations on these matrices. Finally, following Ehrman et al. (2001), confidence bands may be computed by Monte Carlo methods to infer the distributions of the responses. ${ }^{6}$

\section{Empirical analysis}

In this section, I consider an application to real data that illustrates the aforementioned procedures. I employ an updated version of the database used by KPSW to gain insights by comparing the results from their linear and my nonlinear approaches. Whereas they develop both a three-variable and a six-variable models, I only consider their three-variable model of output, consumption and investment to reduce the number of parameters to be

\footnotetext{
${ }^{4}$ Note that, when we assume that the economy remains in a given state after the shock, the backwardlooking responses reduce to the regime-dependent responses by imposing that the probability of this state is one at any date.

${ }^{5}$ According to the NBER, the average duration of recessions in the US economy during the period 1945-1991 (9 cycles) is 11 moths.

${ }^{6}$ In the empirical analysis, computations have been developed with maximum $j$ of 50 since $\sum_{s=1}^{j} R^{s}=$ $(\Upsilon, 0)$ reasonably holds.
} 
estimated within the nonlinear approach. For this attempt, I use the quarterly series $y, c$ and $i$ referred to the logarithms of per capita private gross national product, real consumption expenditures and gross private domestic fixed investment. ${ }^{7}$ The effective sample runs over the period 1953.1-2002.3 with previous observations being left as initial values.

\subsection{Preliminary data analysis}

The findings of KPSW are based on neoclassical growth models with uncertainty. In these models, the logarithms of output, consumption and investment are assumed to be integrated of order one. In addition, these variables share a common stochastic trend and the great ratios of consumption over output and investment over output are stationary stochastic processes along the steady state. This leads KPSW to propose the theoretical cointegrating vectors $(-1,1,0)$ and $(-1,0,1)$. In this section, I try to find empirical evidence regarding the integration and cointegration properties of the data.

The analysis of stationarity is addressed in Panel A of Table1. The first two columns show the results of the augmented Dickey-Fuller and Phillips-Perron tests of the null of non stationarity. The last two columns of this table show the results of the KPSS and Lobato-Robinson tests of the null of stationarity, and both are based on nonparametric results. All of these tests are consistent with the presence of one unit root in the logarithms of the three variables that is removed by taking first differences.

\footnotetext{
${ }^{7}$ Following KPSW, the Citibase series used are GNPC96 minus GGEC96 for output, PCEC96 for consumption and FIPC96 for investment. They are transformed into per capita data with the series CNP16ov.
} 
The cointegration properties of the series are investigated in Panel B of Table 1 by using the nonparametric cointegration analysis advocated by Bierens (1997). The first three rows of this table show the results of the lambda-min test, that is the nonparametric version of the Johansen's maximum eigenvalue statistics This test tests the null hypothesis that there are $r$ cointegrating vectors against the alternative of $r+1$ cointegrating vectors. In this approach, the null is rejected whenever the test statistics is smaller than the critical value. Using this test, I reject the null of zero (versus one) and one (versus two) cointegrating vectors since the test statistics (0.0001 and 0.0013) are smaller than their respective $5 \%$ critical values $(0.0084$ and 0.0017$)$. However, I do not reject the null of two (versus three) cointegrating vectors, since the test statistic becomes 0.42 that is greater than its $5 \%$ critical value of 0.11 . In addition, the last row of this table presents the results of testing the null hypothesis that the cointegrating vectors are $(-1,1,0)$ and $(-1,0,1)$. According to the Bierens' results, the null is rejected whenever the test statistics is greater than the corresponding critical value. Hence, this restriction cannot be rejected at the $5 \%$ level (test statistics of 3.63 versus critical value of 4.36 ). These results suggest that the economic theory predictions are consistent with the data.

\subsection{Markov-switching equilibrium errors}

In this section, I examine the asymmetric short-run adjustment to the long-run equilibrium by analyzing the dynamics of the equilibrium errors. In this attempt, Figure 1 depicts the particular dynamics of the equilibrium errors: while they fluctuate around their respective means, the broad changes of direction in the series seem to mark quite well the NBERreferenced business cycles. During recessions, the value of the first equilibrium error 
is usually high, due to the smoothness of consumption that falls less than output. By contrast, the value of the second equilibrium error declines within recessions due to the higher volatility of investment that falls more than output. In this respect, the first four rows of Table 2 show evidence of this particular dynamics. Using the NBER recessionary data, the first (second) equilibrium error presents a mean that is higher (smaller) than the mean computed using the complete sample, and just the opposite occurs with the mean within expansions. A simple test of the null of no different within-recessions and withinexpansions means is clearly rejected for both cointegrating errors ( $p$-values of 0.001 and less than 0.001 , respectively). As a final check to confirm that equilibrium errors share this business cycle pattern, the last two rows of Table 2 show the $p$-values of the following test. First, I generate a dummy variable $D_{t}$, that equals 1 if $t$ corresponds to NBER recessions and 0 elsewhere. Second, I include this dummy in AR and VAR specifications of the cointegrating errors, with the lag lengths selected by BIC. Third, I test the significance of this dummy in

$$
o_{t}=a+b D_{t}+c_{p}(L) o_{t-1}+d_{p}(L) o_{t-1} D_{t}+e_{1 t}
$$

where $o$ is either $c-y$ or $i-y$ in the AR case for each equilibrium error (fifth row), or a vector of both equilibrium errors in the VAR case (sixth row). In each of these cases, the parameter estimates of the dummy are statistically significant ( $p$-values less than 0.001), indicating that, even though the long-run attractors are assumed to be linear, the dynamics of the equilibrium errors depends on the business cycle.

A natural approach to handle with these findings is the Markov-switching model proposed in (1), with a number of states equal to two. ${ }^{8}$ In order to consider $(-1,1,0)$ and

\footnotetext{
${ }^{8}$ Following the BIC criterium, I selected a lag length of six. Parameters estimates are available upon
} 
$(-1,0,1)$ as cointegrating vectors generating Markov-switching equilibrium errors, I examine the stationarity condition expressed in (3). In this respect, I find that spectral radius of matrix $\mho$ is 0.98 , which guarantees that the Markov-switching dynamics followed by $c_{t}-y_{t}$ and $i_{t}-y_{t}$ is stationary in the sense of Yao (2001) and Francq and Zakoïan (2001). As a robustness check of the Markov-switching assumption, I obtain that the $p$-value of the standard likelihood ratio test of one state is 0.007. Garcia (1998) shows that the asymptotic distribution of this statistics depends on nuisance parameters, and presents critical values for several univariate specifications. Unfortunately, multivariate models are not treated by this author, but the test statistics is so much higher than the standard $5 \%$ critical value to consider that, even though the standard test is not strictly applicable, a rejection of the null appears unavoidable. Finally, Figure 2 displays the filtered probabilities of being in state 2 that comes from this model, along with the NBER recessions. It is easy to interpret state 2 as recessions and the series plotted in this chart as probabilities of being in recession.

\subsection{Markov-switching common trends}

I have stated in Section 2 that a set of Markov-switching equilibrium errors leads to a Markov-switching common trends representation of the variables. In this section, I use this representation to examine the interaction business cycle fluctuations and between secular movements in four stages.

First, is there evidence that the three endogenous variables present asymmetric patterns? In this respect, Figure 3 plots the logarithms of output, consumption and investrequest. 
ment over the effective sample period. Clearly, these variables present an upward trend. However, this trend does not seem to be a smooth curve but rather a sequence of upturns and downturns that are closely related to the NBER business cycles phases. In this respect, the first three rows of Table 2 reveal that the overall average growth rates of these series are positive $(0.49,0.52$, and 0.58 , respectively). However, the average growth rates of these series are negative during the NBER recessions $(-0.83,-0.06$, and -4.11 , respectively). In addition, fourth row of Table 2 confirms that the mean growth rates of these three variables are statistically lower in periods of NBER recessions than in periods of NBER expansions (the $p$-values of the null of no different means are always less than 0.001). Finally, last two rows of Table 2 analyze the significance of the NBER dummy in (12), where $o$ is $\Delta y, \Delta c$, and $\Delta i$ in the univariate specifications (fifth row) and a vector formed by these three variables in the multivariate specification (sixth row). This points out that the official business cycle phases seem to affect the dynamics of these variables, since in each of these cases the $p$-values of the null of no significance of the NBER-dated dummy is always less than 0.001 .

Second, is my Markov-switching common trends representation detecting the main characteristics of the US business cycle features? and what are its advantages, measured in terms of within-sample performance, with respect to the KPSW linear representation? Based on eights lags of $\Delta x_{t}$ (this is the lag length selected by KPSW), the estimates of 
the Markov-switching model are

$$
\left(\begin{array}{c}
y_{t} \\
c_{t} \\
i_{t}
\end{array}\right)=\left(\begin{array}{c}
0.03 \\
(0.01) \\
0.03 \\
(0.01) \\
0.03 \\
(0.01)
\end{array}\right) \tau_{t}+\widehat{C}_{s_{t \downarrow}}^{*}(L) \widehat{\epsilon}_{t}, \text { with }\left\{\begin{array}{c}
\tau_{t}=\underset{(0.02)}{0.23}+\tau_{t-1}+\widehat{\varphi}_{t}, \text { if } s_{t}=1 \\
\tau_{t}=\underset{(0.09)}{-0.76+\tau_{t-1}+\widehat{\varphi}_{t}, \text { if } s_{t}=2}
\end{array},\right.
$$

where standard errors appear in parentheses. In addition, the estimates of the transition probabilities are $\widehat{p}_{11}=0.95$ (standard error of 0.02 ) and $\widehat{p}_{22}=0.68$ (standard error of $0.10)$.

On the one hand, the ability of the MS-CTM representation to characterize the US business cycle features is examined as follows. Figure 4 plots the filtered probabilities that the economy was in regime two as implied by my nonlinear model, along with shaded areas that represent the NBER recessions. It is interesting that the traditional business cycle dates correspond fairly closely to the inferences about the unobservable state variable. In addition and in contrast to the studies in nonlinear cointegration discussed in the introduction, my up-to-date sample period allow me to infer some conclusions about the new century's first recession. The NBER dating procedure requires the examination of numerous ex-post data series so their decisions about the business-cycle turning points are usually slow in forthcoming. In this respect, they announced the last peak of March 2001 in November 2001, but they have not announced the official trough yet. However, I may use the MS-CTM specification to asses when the last recession is over. For this attempt, I follow Hamilton (1989) to split the sample in two subsamples: the recessionary subsample, characterized by periods with probability of recession greater than 0.5 , and the expansionary subsample, characterized by periods with probability of recession smaller 
than 0.5. In addition, I follow Harding and Pagan (2003) to identify the business-cycle peaks and troughs as the last periods of expansions and recessions, respectively. Using this strategy, Table 3 shows reasonable matches between the turning points selected by the MS-CTM specification and the peaks and troughs documented by the NBER, specially in the last five recessions. ${ }^{9}$ In particular, the MS-CTM estimates show evidence to consider that the last US recession ended in the first quarter of 2002, which coincides with the date of the last trough suggested by Chauvet (2002) in an independent work. Finally, another interesting implication of the Markov framework is that one can derive the expected number of quarters that a recession prevails. Conditional on being in state 2 , the expected duration of a typical US recession is $\left(1-\widehat{p}_{22}\right)^{-1}$ or 3.12 quarters, and the expected duration of an expansion is likewise $\left(1-\widehat{p}_{11}\right)^{-1}$ or 20 quarters. These estimates are close to the historical average duration of recessions (3.66 quarters) and expansions (19.37 quarters) according to the NBER figures. ${ }^{10}$

On the other hand, the MS-CTM within-sample performance is evaluated in the first row of Table 4. This shows that the one-quarter-ahead forecast relative mean squared errors of the nonlinear model over the linear model are $0.66,0.75$, and 0.70 for each of the three variables. In addition, to avoid the possibility of getting a spuriously good fit, I compute several tests to evaluate the ability of these models to predict the endogenous variables. In particular, rows two to six of Table 4 display the $p$-values of the following tests of the null of no difference in the accuracy of the competing linear and nonlin-

\footnotetext{
${ }^{9}$ On average, the MS-CTM specification identifies the peaks with a lag of 0.4 quarters and the troughs with a lead of 0.6 quarters.

${ }^{10}$ According to Chauvet (2002), in these computations I use that the last trough was in 2002.1.
} 
ear forecasts: the Diebold-Mariano, Modified-Diebold-Mariano, Wilcoxon, naive F test, Morgan-Granger-Newbold, and Meese-Rogoff tests, all of them described in Diebold and Mariano (1995) and Harvey et al. (1997). The $p$-value of each of these tests is sufficiently low to confirm the superior predicting ability of the nonlinear model. In addition, last row of Table 4 presents the $p$-values of the forecast encompassing test based on testing the significativity of $\alpha_{1}$ in the OLS regression

$$
l_{t}-\widehat{l}_{t, s w}=\alpha_{0}+\alpha_{1} \widehat{l}_{t, l i n}+e_{2 t},
$$

where $l_{t}$ is one of the endogenous variables, and $\widehat{l}_{t, s w}\left(\widehat{l}_{t, l i n}\right)$ is its one-step-ahead in-sample forecast computed from the Markov-switching (linear) common trends model. These $p$ values indicate that forecasts from the nonlinear model encompass the forecasts from the linear model.

Third, how does the model capture the asymmetric adjustment between recessions and expansions to the long run equilibrium? In the introduction, I postulate that the dynamics of the error correction mechanism may be asymmetric within the business cycle due to both market mechanisms and policy interventions. I introduce this possibility by allowing the loading matrix $\alpha_{s_{t}}$ in the MS-VECM to be state dependent. This matrix can be interpreted as a measure of the speed by which the system correct last period's equilibrium errors. In this respect, Table 5 contains the estimated parameters and standard errors for this matrix in each state. These estimates show two types of business cycle asymmetries in the error correction. First, asymmetries in the sign of the adjustment since the loading matrix reverses the sign when the phase of the business cycle changes. This may be due to the business-cycle dynamics of the equilibrium errors: during recessions $c-y$ tends 
to rise and $i-y$ tends to fall, whereas during expansions $c-y$ tends to fall and $i-y$ tends to rise. Second, and most interesting, asymmetries in the strength of convergence towards the equilibrium since the absolute size of the loading matrix parameters is bigger in the second state compared with the first state. This finding supports the view that the economy reacts more drastically against the adverse economic situation of recessions, than it reacts to correct the deviations from the equilibrium associated with expansions.

Fourth, is my nonlinear model able to detect the impacts of trend shocks over business cycle horizons obtained by the KPSW standard approach? Figure 5 shows the naïve estimates of the backward-looking responses together with the one standard deviation confidence intervals. In order to facilitate comparisons with the KPSW results and due to the history dependence of the backward-looking responses, this figure reports the responses to a shock hitting the system in 1988.4. My backward-looking responses are comparable to the linear responses of KPSW, specially for output and investment. ${ }^{11}$ That is, the responses in 1988.4 are maximum for shocks hitting the system in $1988.4-1988.1$, are declining for shocks produced between 1988.1 and 1986.2, and reach the long-run level for shocks occurring before 1986. In addition, these estimates imply a variance decomposition (not shown) for which shocks produced about three or four years prior to 1988.4 are able to explain between 60 and 80 per cent of the current variation in the endogenous variables, which agrees with the linear findings of KPSW.

Finally, how strong are the permanent effects of business-cycle fluctuations? On the one hand, the MS-CTM proposal shows that the common stochastic trend shared by output,

\footnotetext{
${ }^{11}$ Note that, for linear models, the responses at $t$ to shocks in $t-j$ coincide with the responses at $t+j$ to shocks in $t$.
} 
consumption and investment, is characterized by regime switching in its growth rate. This Hamilton type of asymmetry implies that during a recession the economy is hit by large negative shocks pushing the trend growth rate down. Specifically, in line with Kim et al. (2002) but in contrast to Kim and Piger (2002), I find that the growth rate is negative $(-0.76)$ during recessions which implies that when the negative recessionary shocks vanish, the trend level is lower than if the recession had never occurred. To illustrate the effects of incorporating these slowdowns in the trend during recessions, Figure 6 plots the estimates of the Markov-switching common trend, along with the NBER schedule. On the other hand, Hamilton (1989) propose a measure of the permanent effects of recessions in the level of the common trend. In this respect, if the economy is currently in a recession rather than in an expansion, the consequences for the long-run future level of the trend are given by the expression:

$$
H=\frac{\left(\vartheta_{s_{t}=2}-\vartheta_{s_{t}=1}\right)\left(-1+p_{11}+p_{22}\right)}{2-p_{11}-p_{22}}
$$

Using the MS-CTM estimates, I obtain that a typical recession leads to a $1.68 \%$ permanent drop in the common trend that is roughly the half of the value reported by Hamilton (1989). Kim and Piger (2002) and Kim et al. (2002) suggest that a possible explanation for the higher negative effects of recessions detected by the Hamilton model may be its lack of a mechanism to capture transitory types of asymmetry.

\section{Conclusion}

As pointed out by Stock and Watson (1988b), the literature on multivariate empirical analysis suggests that trends and business cycle movements appear to be related. If this is 
the case, theories explaining only growth or only cycles cannot provide adequate insights. In this respect, KPSW have shown that innovations in trends play an important role in macroeconomic variables at business cycle horizons. This paper extends the Stock-Watson common trends representation to allow for Markov-switching business cycle asymmetries in both its permanent component and its transitory component. Within this framework, I investigate the long-run consequences of business cycle fluctuations.

To address this question, I start by considering equilibrium errors that, even though they fluctuate around a linear long-run attractor, the dynamic adjustment toward the attractor may present business cycle asymmetries. I show that this particular dynamics of the equilibrium errors lead to a Markov-switching common trend representation of the variables that is able to consider the bidirectional relationship between trends and business cycle fluctuations. According to the standard linear analysis, I find that trend shocks cause important effects in the variables within the business cycle horizon. In addition, I conclude that severe recessions will also damage the long-run growth.

I end this conclusion with some suggestions for further research in nonlinear long-run adjustment mechanisms to long-run equilibriums. Among others, Krolzig (1997, 1999), Krolzig and Toro (1999), Psaradakis et al. (2001), and Krolzig et al. (2002) incorporate the asymmetric adjustment to linear vector error equilibrium models by allowing for Markovswitching parameters. In this paper, I discuss the alternative Markov-switching common trends representation. I consider that a natural direction for further research is analyzing the nonlinear common trends representations that may be derived from other nonlinear equilibrium error models suggested in the literature: the threshold approach of Balke and Fomby (1997), the bilinear model approach of Peel and Davidson (1998), and the smooth 
transition regression approach of Rothman et al. (2001). 


\section{Appendix A: Switching equilibrium errors lead to switching VECM.}

Let me assume that $x_{t}$ is a $(n \times 1)$ vector of nonstationary variables and that $\beta$ is the $(n \times r)$ cointegrating matrix such that $z_{t}=\beta^{\prime} x_{t}$ is the stationary $(r \times 1)$ vector of equilibrium errors that follows the stationary MS-VAR $z_{t}=m_{s_{t}}+A_{s_{t}}(L) z_{t-1}+e_{t}$ appearing in Section 2. I can always choose an $(n \times k)$ matrix $\beta^{\dagger}$ such that $\beta^{\dagger \prime} \beta=0$ and $\beta^{\dagger \prime} \beta^{\dagger}=I_{k}$. Let $w_{t}$ be the $(k \times 1)$ vector $\beta^{\dagger \prime} x_{t}$ such that $\Delta w_{t}=n+G(L) \Delta w_{t-1}+\eta_{t}$, where $\Delta=(1-L), G(L)=\left(G^{1}+\cdots+G^{p} L^{p-1}\right)$, and $\eta_{t} \sim N\left(0, I_{k}\right)$, is regime-independent. Note that, as in Psaradakis et al. (2001), it is not necessary the extra assumption that $\Delta w_{t}$ is a MS-VAR.

It follows that, after a little of algebra, $A_{s_{t}}(L)$ can be written as $A_{s_{t}}(1)+A_{s_{t}}^{*}(L)(1-L)$, where $A_{s_{t}}(1)=\sum_{i=1}^{p} A_{s_{t}}^{i}, A_{s_{t}}^{*}(L)=A_{s_{t}}^{* 1}+\ldots+A_{s_{t}}^{* p-1} L^{p-2}$, and $A_{s_{t}}^{* j}=-\sum_{i=j+1}^{p+1} A_{s_{t}}^{i}$. This allows me to show that the expression

$$
\beta^{\prime} \Delta x_{t}=m_{s_{t}}+A_{s_{t}}^{*}(L) \beta^{\prime} \Delta x_{t-1}+\left[A_{s_{t}}(1)-I_{r}\right] z_{t-1}+e_{t}
$$

holds. On the other hand, I can establish that

$$
\beta^{\dagger \prime} \Delta x_{t}=n+G(L) \beta^{\dagger \prime} \Delta x_{t-1}+\eta_{t}
$$

To simplify notation, I use the symbols $\Theta$ and $\Xi_{s_{t}}$ for $\left(\beta, \beta^{\dagger}\right)^{\prime}$ and $\left(m_{s_{t}}^{\prime}, n^{\prime}\right)^{\prime}$ respectively. Thus, expressions $(A .1)$ and (A.2) immediately lead to the MS-VECM of Section 2, with

$$
\begin{array}{r}
\mu_{s_{t}}=\Theta^{-1} \Xi_{s_{t}}, \alpha_{s_{t}}=\Theta^{-1}\left(\left(A_{s_{t}}(1)-I_{n}\right)^{\prime}, 0^{\prime}\right)^{\prime}, \epsilon_{t}=\left(e_{t}^{\prime}, \eta_{t}^{\prime}\right)^{\prime} \text {, and } \\
\pi_{s_{t}}(L)=\Theta^{-1}\left(\begin{array}{cc}
A_{s_{t}}^{*}(L) & 0 \\
0 & G(L)
\end{array}\right) \Theta .
\end{array}
$$


Appendix B: Moving average parameters depend on previous states.

Let $y_{t}$ be a $(n \times 1)$ vector of stationary variables (minus its conditional mean $\varsigma_{s_{t}}$ ) evolving according to a MS-VAR(p), that is:

$$
y_{t}=b_{s_{t}}^{1} y_{t-1}+\ldots+b_{s_{t}}^{p} y_{t-p}+\epsilon_{t}^{*} .
$$

This may be written as a MS-VAR(1) as follows

$$
Y_{t}=B_{s_{t}} Y_{t-1}+E_{t},
$$

with the $(n p \times 1),(n p \times n p)$, and $(n p \times 1)$ matrices $Y_{t}, B_{s_{t}}$, and $E_{t}$ defined as

$$
Y_{t}=\left[\begin{array}{c}
y_{t} \\
\vdots \\
y_{t-p+1}
\end{array}\right], B_{s_{t}}=\left[\begin{array}{ccccc}
b_{s_{t}}^{1} & b_{s_{t}}^{2} & \cdots & b_{s_{t}}^{p-1} & b_{s_{t}}^{p} \\
I_{n} & 0_{n} & \cdots & 0_{n} & 0_{n} \\
\vdots & \vdots & \cdots & \vdots & \vdots \\
0_{n} & 0_{n} & \cdots & I_{n} & 0_{n}
\end{array}\right], E_{t}\left[\begin{array}{c}
\epsilon_{t}^{*} \\
0_{n} \\
\vdots \\
0_{n}
\end{array}\right] .
$$

Assuming stationarity, recursive substitution in expression (B.2) leads to

$$
Y_{t}=E_{t}+B_{s_{t}} E_{t-1}+B_{s_{t}} B_{s_{t-1}} E_{t-2}+B_{s_{t}} B_{s_{t-1}} B_{s_{t-2}} E_{t-3}+\ldots
$$

which implies that the $\mathrm{j}$-th moving average matrix is in fact the upper-left block of the matrix $B_{s_{t}} \cdots B_{s_{t-(j-1)}}$.

Appendix C: Deriving expression $C_{s_{t \downarrow}}(L)=C(1)+(1-L) C_{s_{t \downarrow}}^{*}(L)$.

Recall the state-dependent parameters of the moving average expression

$$
C_{s_{t \downarrow}}(L)=\left(I+C_{s_{t}}^{1} L+C_{s_{t}, s_{t-1}}^{2} L^{2}+C_{s_{t}, s_{t-2}}^{3} L^{3}+\ldots\right) .
$$

Le me define $C(1)$ as follows

$$
C(1)=I+C^{1}+C^{2}+C^{3}+\ldots
$$


where $C^{j}=\sum_{i_{0}=1}^{q} \ldots \sum_{i_{j-1}=1}^{q} P\left(s_{t}=i_{0}, \ldots, s_{t-(j-1)}=i_{j-1}\right) C_{s_{t}, s_{t-(j-1)}}^{j}$. Thus, expression $(C .1)$ may be rewritten as

$$
\begin{aligned}
& C_{s_{t \downarrow}}(L)=C(1)+\{\underbrace{(-C(1)+I)}_{C^{* 0}}-\underbrace{(-C(1)+I)}_{C^{* 0}} L\}+ \\
& \{\underbrace{\left(-C(1)+I+C_{s_{t}}^{1}\right)}_{C_{s_{t}}^{* 1}} L-\underbrace{\left(-C(1)+I+C_{s_{t-1}}^{1}\right)}_{C_{s_{t-1}}^{* 1}} L^{2}\}+
\end{aligned}
$$

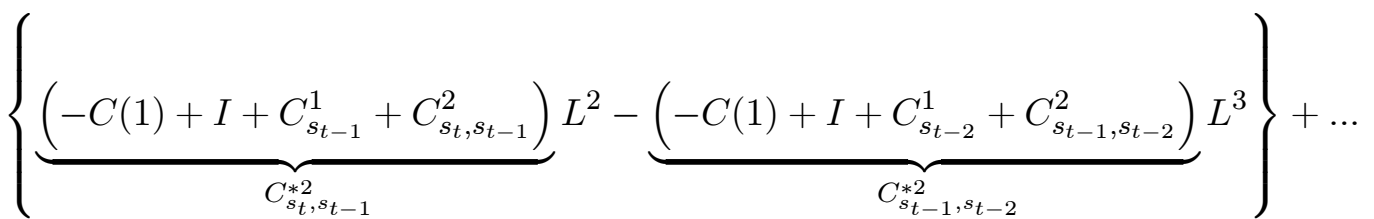

This implies that expression $C_{s_{t \downarrow}}(L)=C(1)+(1-L) C_{s_{t \downarrow}}^{*}(L)$ holds, with

$$
C_{s_{t}, s_{t-(j-1)}}^{* j}=-C(1)+I+C_{s_{t-(j-1)}}^{1}+C_{s_{t-(j-2)}, s_{t-(j-1)}}^{2}+\ldots+C_{s_{t}, s_{t-(j-1)}}^{j} .
$$

\section{Appendix D: Moving average parameters and backward-looking responses.}

To deduce the proof, let me define some additional notation to those stated in Sections 2 and 3. Let me define $\xi_{t / t}$ as the $(q \times 1)$ vector whose i-th element is $P\left(s_{t}=i \mid \chi_{t}\right)$, with $\chi_{t}$ the information set up to $t, \xi_{t / t-h}$ as $P^{h} \xi_{t-h / t-h}$, and $e_{j}^{\prime}$ the $(1 \times q)$ row $j$ of the identity matrix. For any $(a \times b)$ matrix $W$ let me define the $(a n p \times b n p)$ matrix $W^{*}=\left(W \otimes I_{n p}\right)$. In this way, I introduce the matrices $P^{\prime *}, \xi_{t / t}^{*}$, and $\widetilde{\xi}_{h / h-1}^{*}$, with $\widetilde{\xi}_{t / t-1}$ being the $(q \times q)$ diagonal matrix whose $j$-th diagonal element is $e_{j}^{\prime} \xi_{t / t} / e_{j}^{\prime} \xi_{t / t-1}$. Let $M$ be the $(n \times n)$ matrix $\left(\beta^{\dagger}, \beta\right)^{\prime}$, and $D$ be the $(n \times n)$ matrix with ones in the last $r$ elements of its main diagonal and zeroes elsewhere. Let me consider the $(n p \times n p)$ matrix $B_{j}$ defined in Appendix B, the $(n p \times n p q)$ matrix $b=\left(B_{1}, \ldots B_{q}\right)$, and the $(n p q \times n p q)$ block-diagonal matrix $B$, with 
$b$ in its main block diagonal and zeros elsewhere. Finally, let me define the $(n p q \times n p q)$ matrix

$$
\Phi_{t / t-j+1}=\widetilde{\xi}_{t / t-1}^{*} P^{\prime *} B \widetilde{\xi}_{t-1 / t-2}^{*} P^{\prime *} B \ldots \widetilde{\xi}_{t-(j-1) / t-j}^{*} P^{\prime *} B
$$

For this attempt, I note that assuming stationarity and a conditional expectation equal to zero, Appendix C allows me to write the MS-RVAR specification as

$$
y_{t}=\epsilon_{t}^{*}+F_{s t}^{1} \epsilon_{t-1}^{*}+F_{s_{t}, s_{t-1}}^{2} \epsilon_{t-2}^{*}+\ldots
$$

where $F_{s_{t}, s_{t-j+1}}^{j}=J B_{s_{t}} B_{s_{t-1}} \cdots B_{s_{t-j+1}} J^{\prime}$, and $J$ is the $(n \times n q)$ matrix $\left(I_{n} 0 \ldots 0\right)$. The natural estimator of $B_{s_{t}} \ldots B_{s_{t-j}}$ is the expression

$$
\sum_{i_{0}=1}^{q} \ldots \sum_{i_{j}=1}^{q} P\left(s_{t-j}=i_{j}, \ldots, s_{t}=i_{0} \mid \chi_{t}\right) B_{s_{t}} \ldots B_{s_{t-j}}
$$

where the joint probabilities, using the properties of a Markov structure, may be expressed as

$$
\begin{aligned}
P\left(s_{t-j}\right. & \left.=i_{j}, \ldots, s_{t}=i_{0} \mid \chi_{t}\right) \\
& =\left(e_{i_{0}}^{\prime} \xi_{t / t}\right) \frac{\left(e_{i_{0}}^{\prime} P^{\prime} e_{i_{1}}\right)\left(e_{i_{1}}^{\prime} \xi_{t-1 / t-1}\right)}{\left(e_{i_{0}}^{\prime} \xi_{t / t-1}\right)} \cdots \frac{\left(e_{i_{j-1}}^{\prime} P^{\prime} e_{i_{j}}\right)\left(e_{i_{j}}^{\prime} \xi_{t-j / j-1}\right)}{\left(e_{i_{j-1}}^{\prime} \xi_{t-j+1 / t-j}\right)} .
\end{aligned}
$$

Thus, (D.3) leads to the moving average parameters of the MS-RVAR estimates

$$
F^{j}=J b \Phi_{t / t-j+1} \xi_{t-j+1 / t-j+1}^{*} J^{\prime}
$$

for $j>1$, with $F^{1}=J b \xi_{t / t}^{*} J^{\prime}$. Finally, following Warne (1993), the backward-looking responses $R^{j}$ may be iteratively calculated as $M^{-1}\left(F^{j}-D F^{j-1}\right) M \Gamma^{-1}$.

As an example to show you how (D.5) is recursively constructed, I derive the estimate of $\sum_{i_{0}=1}^{q} \sum_{i_{1}=1}^{q} P\left(s_{t-1}=i_{1}, s_{t}=i_{0} \mid \chi_{t}\right) B_{s_{t}} B_{s_{t-1}}$. Using that $\left(e_{1}, \ldots, e_{q}\right)=\left(e_{1}, \ldots, e_{q}\right)^{\prime}=I_{q}$, the 
expression for the joint probabilities is

$$
\begin{aligned}
& P\left(s_{t-1}=i_{1}, s_{t}=i_{0} \mid \chi_{t}\right)=P\left(s_{t}=i_{0} \mid \chi_{t}\right) P\left(s_{t-1}=i_{1} \mid \chi_{t}, s_{t}=i_{0}\right) \\
& =P\left(s_{t}=i_{0} \mid \chi_{t}\right) P\left(s_{t-1}=i_{1} \mid \chi_{t-1}, s_{t}=i_{0}\right)=\left(e_{i_{0}}^{\prime} \xi_{t / t}\right) \frac{P\left(s_{t-1}=i_{1} \mid \chi_{t-1}, s_{t}=i_{0}\right)}{P\left(s_{t}=i_{0} \mid \chi_{t-1}\right)} \\
& \quad=\left(e_{i_{0}}^{\prime} \xi_{t / t}\right) \frac{\left(e_{i_{0}}^{\prime} P^{\prime} e_{i_{1}}\right)\left(e_{i_{1}}^{\prime} \xi_{t-1 / t-1}\right)}{\left(e_{i_{0}}^{\prime} \xi_{t / t-1}\right)} .
\end{aligned}
$$

The estimates become:

$$
\begin{aligned}
& \sum_{i_{0}} \sum_{i_{1}} P\left(s_{t-1}=i_{1}, s_{t}=i_{0} \mid \chi_{t}\right) B_{i_{0}} B_{i_{1}} \\
& =\sum_{i_{0}} B_{i_{0}} \frac{\left(e_{i_{0}}^{\prime} \xi_{t / t}\right)}{\left(e_{i_{0}}^{\prime} \xi_{t / t-1}\right)} \quad \underbrace{\sum_{i_{1}}\left(e_{i_{0}}^{\prime} P^{\prime} e_{i_{1}}\right) B_{i_{1}}\left(e_{i_{1}}^{\prime} \xi_{t-1 / t-1}\right)} \\
& {\left[\left(e_{i_{0}}^{\prime} P^{\prime} e_{1}\right) B_{1}, \ldots,\left(e_{i_{0}}^{\prime} P^{\prime} e_{q}\right) B_{q}\right]\left[\begin{array}{c}
e_{1}^{\prime} \xi_{t-1 / t-1} I_{n p} \\
\ldots \\
e_{q}^{\prime} \xi_{t-1 / t-1} I_{n p}
\end{array}\right]} \\
& {\left[\left(e_{i_{0}}^{\prime} P^{\prime}\left(e_{1}, \ldots, e_{q}\right)\right) \otimes I_{n p}\right] B \xi_{t-1 / t-1}^{*}} \\
& \left(e_{i_{0}}^{\prime} \otimes I_{n p}\right)\left(P^{\prime} \otimes I_{n p}\right) B \xi_{t-1 / t-1}^{*} \\
& =\underbrace{\left(B_{1}, \ldots, B_{q}\right)}_{b} \underbrace{\left(\begin{array}{ccc}
\left(\frac{e_{1}^{\prime} \xi_{t / t}}{e_{1}^{\prime} \xi_{t / t-1}}\right) I_{n p} & 0 \\
& \ldots & \\
0 & & \left(\frac{e_{q}^{\prime} \xi_{t / t}}{e_{q}^{\prime} \xi_{t / t-1}}\right) I_{n p}
\end{array}\right)}_{\tilde{\xi}_{t / t-1}^{*}} \underbrace{\left(\begin{array}{c}
e_{1}^{\prime} \otimes I_{n p} \\
\ldots \\
e_{q}^{\prime} \otimes I_{n p}
\end{array}\right)}_{I_{n p q}} P^{\prime *} B \xi_{t-1 / t-1}^{*} \\
& =b \widetilde{\xi}_{t / t-1}^{*} P^{\prime *} B \xi_{t-1 / t-1}^{*} .
\end{aligned}
$$




\section{References}

[1] Balke, N., Fomby, T., 1997. Threshold cointegration. International Economic Review 38, No 3, 627-645.

[2] Bierens, H., 1997. Nonparametric cointegration analysis. Journal of Econometrics 77, $379-404$.

[3] Caballero, J., Hammour, M., 1994. The cleansing effect of recessions. The American Economic Review 84, 1350-1368.

[4] Camacho, M., 2001. Three essays in nonlinear macroeconometrics. Ph. D. dissertation, Universitat Autònoma de Barcelona, Spain.

[5] Chauvet, M., 1999. Stock market fluctuations and the business cycle. Journal of Economic and Social Measurement 25, 235-257.

[6] Coakley, J., Fuertes, A., 2001. Nonparametric cointegration analysis of real exchange rates. Applied Financial Economics 11, 1-8.

[7] Diebold, F., Mariano R., 1995. Comparing predictive accuracy. Journal of Business and Economic Statistics 13, 253-263.

[8] Ehrmann., M., 2000. Firm size and monetary policy transmission: evidence from German business survey data. ECB working paper 21.

[9] Ehrmann, M., Elison, M., Valla, N., 2001. Regime-dependent impulse response functions in a Markov-switching vector autoregression model. Bank of Finland working paper no. 11 . 
[10] Ehrmann, M., Elison, M., Valla, N., 2003. Regime-dependent impulse response functions in a Markov-switching vector autoregression model. Economics Letters, 295-299.

[11] Enders, W., Siklos, P. 2001. Cointegration and threshold adjustment. Journal of Business and Economic Statistics 19, 166-177.

[12] Engel, R., Granger, C., 1987. Cointegration and error correction: representation, estimation and testing. Econometrica 55, No. 2, 251-276.

[13] Francq, C., Zakoïan, J-M., 2001. Stationarity of multivariate Markov-switching ARMA models. Journal of Econometrics 102, 339-364.

[14] Francis, N. and Owyang, M., 2003. Asymmetric common trends: an application of minetary policy in Markov-switching VECM. Federal Reserve Bank of St. Louis working paper 2003-001B.

[15] Friedman, M., 1993. The plucking model of business fluctuations revisited. Economic Inquiry $31,171-177$.

[16] Garcia , R., 1998. Asymptotic distribution of the likelihood ratio test in Markov switching models. International Economic Review 39: 763-788.

[17] Garcia, R., Schaller, H., 2002. Are the Effects of monetary policy asymmetric?. Economic Enquiry 40, No. 1, 102-119.

[18] Gonzalo, J., Ng, S., 2001. A systematic framework for analyzing the dynamics effects of permanent and transitory shocks. Journal of Economic Dynamics and Control 10, No. 25, 1527-1546. 
[19] Granger, C., Inoue, T., Morin, N., 1997. Nonlinear stochastic trends. Journal of Econometrics 81, 65-92.

[20] Hamilton, J., 1989. A new approach to the economic analysis of nonstationary time series and the business cycles. Econometrica 57, 357-384.

[21] Harding, D., Pagan, A., 2003. A comparison of two business cycle dating methods. Journal of Economic Dynamics and Control 27, 1681-1690.

[22] Harvey, D., Leybourne, S., Newbold, P., 1997. Testing the equality of prediction mean squared errors. International Journal of Forecasting 13: 281-291.

[23] King, R., Plosser, CH., Stock, J., Watson, M., 1991. Stochastic trends and economic fluctuations. The American Economic Review 81, No. 4, 819-840.

[24] Kim, Ch., Nelson, Ch., 1999. Friedman's plucking model of business fluctuations: tests and estimates of permanent and transitory components. Journal of Money, Credit, and Banking 31, 317-334.

[25] Kim, Ch., Piger, J., 2002. Common stochastic trends, common cycles, and asymmetry in economic fluctuations. Journal of Monetary Economics 49, 1189-1211.

[26] Kim, Ch., Morley, J., Piger, J., 2002. Nonlineatity and the permanent effects of recessions. Federal Reserve Bank of St. Louis working paper 2002-014.

[27] Koop, G., Pesaran, M., Potter, S., 1996. Impulse response analysis in nonlinear multivariate models. Journal of Econometrics 74, 119-147..

[28] Krolzig, H.-M. 1997. Markov-switching vector autoregression. Berlin: Springer. 
[29] Krolzig, H.-M. 1999. Statistical analysis of cointegrated VAR processes with Markovian regime shifts. University of Oxford, mimeo.

[30] Krolzig, H.-M, Toro, J., 1999. A new approach to the analysis of shocks and the cycle in a model of output and employment. European University Institute working paper no. $99 / 30$.

[31] Krolzig, H.-M., Marcellino, M., and Mizon, G., 2002. A Markov-switching vector equilibrium correction model of the UK Labor Market. Empirical Economics 27, 233254.

[32] Mellander, E., Vredin, A., Warne, A., 1992. Stochastic trends and economic fluctuations in a small open economy. Journal of Applied Econometrics 7, 369-394.

[33] Paap, R., van Dijk, H.K., 2003. Bayes estimates of Markov trends in possibly cointegrated series: An Application to US Consumption and Income. Journal of Business and Economics Statistics, forthcoming.

[34] Peel, D., Davidson, J., 1998. A non-linear error correction mechanism based on the bilinear model. Economics Letters 58, 165-170.

[35] Psaradakis, Z., Sola, M., Spagnolo, F., 2001. On Markov error-correction models. Mimeo, School of Economics, Mathematics and Statistics, Brikbeck College, London.

[36] Rothman, P., van Dijk, D., Franses, P. 2001. A multivariate analysis of the relationship between money and output. Macroeconomic Dynamics 5, 506-532.

[37] Stock, J., Watson, W., 1988a. Testing for common trends. Journal of the Royal Statistical Association 83, No 404, 1097-1107. 
[38] Stock, J., Watson, W., 1988b. Variable trends in economic time series. Journal of Economic Perspectives 2, 147-174.

[39] Tobin, J., 1980. Stabilization policy ten years after. Brooking Papers on Economic Activity 1, 19-90.

[40] van Dick, D:, Franses, P. 2000. Nonlinear error-correction models for interest rates in the Netherlands, in W.A. Barnett, D.F. Hendry, S. Hylleberg, T. Teräsvirta, D. Tjøstheim, and A. Würtz (ed.) Nonlinear Econometric Modelling-Proceedings of the 6th (EC) 2nd meeting, Cambridge: Cambridge University Press. 203-227

[41] Warne, A., 1993. A common trend model: identification, estimation and inference. Mimeo, Institute for International Economic Studies, Stockholm University, Sweden.

[42] Yao J., 2001. On square-integrability of an AR process with Markov switching. Statistics and Probability Letters 52, 265-270. 
Table 1. Unit root and cointegration analysis.

Panel A. Unit root tests

\begin{tabular}{ccccc}
\hline & $\begin{array}{c}A D F \\
(-3.43)\end{array}$ & $\underset{(-3.43)}{P P}$ & $\begin{array}{c}\text { KPSS } \\
(-0.46)\end{array}$ & $\begin{array}{c}\text { LRo } \\
(-1.96)\end{array}$ \\
\hline$y$ & -2.98 & -2.85 & 1.72 & -2.74 \\
$c$ & -2.04 & -2.25 & 1.73 & -2.76 \\
$i$ & -3.25 & -3.21 & 1.63 & -2.75 \\
$\Delta y$ & -10.07 & -10.15 & 0.05 & -0.53 \\
$\Delta c$ & -7.61 & -11.35 & 0.06 & -0.58 \\
$\Delta i$ & -11.87 & -11.89 & 0.02 & -0.24 \\
\hline
\end{tabular}

Panel B. Cointegration tests

\begin{tabular}{ccc}
\hline Hypothesis & statistics & $5 \%$ crit val \\
\hline$r=0 \backslash r=1$ & 0.0001 & 0.0084 \\
$r=1 \backslash r=2$ & 0.0013 & 0.0017 \\
$r=2 \backslash r=3$ & 0.4294 & 0.1105 \\
$\beta^{\prime}=\left(\begin{array}{ccc}-1 & 1 & 0 \\
-1 & 0 & 1\end{array}\right)$ & 3.6328 & 4.3600 \\
\hline
\end{tabular}

Notes. Panel A shows the Augmented Dickey-Fuller (ADF), Phillip-Perron (PP), KPSS and Lobato-Robinson (LRo) unit root tests, with $5 \%$ critical values in parentheses. First three rows of Panel B show the Bierens' nonparametric cointegration tests (reject if statistics is lower than $5 \%$ critical values). Last row shows the results of restricting the cointegrating matrix (reject if statistics is greater than $5 \%$ critical value). 
Table 2. Business cycles asymmetries.

\begin{tabular}{|c|cc|ccc|}
\cline { 2 - 6 } \multicolumn{1}{c|}{} & $c-y$ & $i-y$ & $\Delta y$ & $\Delta c$ & $\Delta i$ \\
\hline Mean & -0.170 & -1.745 & 0.498 & 0.527 & 0.586 \\
Mean-E & -0.174 & -1.728 & 0.875 & 0.692 & 1.937 \\
Mean-R & -0.159 & -1.803 & -0.839 & -0.069 & -4.116 \\
Diff. means test & 0.001 & $<0.001$ & $<0.001$ & $<0.001$ & $<0.001$ \\
\hline AR-dummy & $<0.001$ & $<0.001$ & $<0.001$ & $<0.001$ & $<0.001$ \\
VAR-dummy & $<0.001$ & & $<0.001$ & \\
\hline
\end{tabular}

Notes. Variables, $\Delta y, \Delta c$ and $\Delta i$ refer to the growth rate of per capita gross national product, real consumption expenditures and gross private domestic fixed investment. First row shows sample means computed in the period 1949.1-1988.4. Second (third) row shows means computed within the NBER expansions (recessions). Fourth row presents the $p$ values of the test of different means in these subsamples. Finally, let $D_{t}$ a dummy that takes value 1 within the NBER recessions and 0 elsewhere. Last two rows present the $p$-values of the significativity test of this dummy in

$$
o_{t}=a+b D_{t}+c_{p}(L) o_{t-1}+d_{p}(L) o_{t-1} D_{t}+e_{1 t}
$$

In fifth row, $o$ refers to each of the five variables $c-y, i-y, \Delta y, \Delta c$, and $\Delta i$ respectively. In the last row, $o$ refers to either $(c-y, i-y)^{\prime}$ in the first entry, or $(\Delta y, \Delta c, \Delta i)^{\prime}$ in the second entry. In each of these regressions, $p$ was selected by BIC. 
Table 3. Comparing business-cycle turning points.

\begin{tabular}{cccc}
\multicolumn{2}{c}{ Peaks } & \multicolumn{2}{c}{ Troughs } \\
\hline MS-CTM & NBER & MS-CTM & NBER \\
\hline 53.3 & 53.2 & 53.4 & 54.2 \\
57.3 & 57.3 & 58.1 & 58.2 \\
60.2 & 60.2 & 60.3 & 61.1 \\
70.3 & 69.4 & 70.4 & 70.4 \\
73.3 & 73.4 & 75.1 & 75.1 \\
79.4 & 80.1 & 80.4 & 80.3 \\
81.4 & 81.3 & 82.3 & 82.4 \\
90.3 & 90.3 & 91.1 & 91.1 \\
01.2 & 01.1 & 02.1 & - \\
\hline
\end{tabular}

Notes. This table shows the business-cycle turning points selected by the MS-CTM specification and by the NBER, respectively. Following Harding and Pagan (2003), I compute the peaks and troughs from the MS-CTM specification as follows. First, according to the filtered probability being of state 2 , I split the sample in recessions (whenever the probability is greater than 0.5 ) and expansions (whenever the probability is smaller than 0.5). Second, I select the troughs as the last periods of recessions and the peaks as the last periods of expansions. 
Table 4. Comparing in-sample forecasting accuracy.

\begin{tabular}{|c|ccc|}
\cline { 2 - 4 } \multicolumn{1}{c|}{} & $y$ & $c$ & $i$ \\
\hline RMSE & 0.658 & 0.747 & 0.699 \\
\hline DM & 0.004 & 0.0016 & 0.004 \\
MDM & 0.005 & 0.0017 & 0.005 \\
W & $<0.001$ & $<0.001$ & $<0.001$ \\
F & 0.001 & 0.020 & 0.006 \\
MGN & $<0.001$ & $<0.001$ & $<0.001$ \\
MR & $<0.001$ & 0.001 & $<0.001$ \\
\hline Encompass & 0.946 & 0.999 & 0.968 \\
\hline
\end{tabular}

Notes. Variables, $y, c$ and $i$ refer to per capita gross national product, real consumption expenditures and gross private domestic fixed investment. RMSE refers to the relative mean squared error of the Markov-switching over the linear common trends models. Entries in rows two to seven show the $p$-values of the following test of equal forecast accuracy: DM (Diebold-Mariano), MDM (Modified-DM), W (Wilcoxon), F (naive F test), MGN (Morgan-Granger-Newbold), and MR (Meese-Rogoff), all of them described in Diebold and Mariano (1995) and Harvey et al. (1997). Last row presents the $p$-values of the forecast encompassing test based upon the significativity test of $\alpha_{1}$ in the OLS regression

$$
l_{t}-\widehat{l}_{t, s w}=\alpha_{0}+\alpha_{1} \widehat{l}_{t, l i n}+e_{2 t},
$$

where $l_{t}$ is one of the endogenous variables and $\widehat{l}_{t, s w}\left(\widehat{l}_{t, l i n}\right)$ is its one-step ahead in-sample forecast computed from the Markov-switching (linear) common trends model. 
Table 5. Asymmetric error correction.

\begin{tabular}{|c|c|c|c|}
\hline \multicolumn{2}{|c|}{$\widehat{\alpha}_{s_{t}=1}$} & \multicolumn{2}{|c|}{$\widehat{\alpha}_{s_{t}=2}$} \\
\hline $\begin{array}{c}-0.09 \\
(0.02)\end{array}$ & $\begin{array}{c}0.08 \\
(0.04)\end{array}$ & $\begin{array}{l}0.11 \\
(0.03)\end{array}$ & $\begin{array}{c}-0.14 \\
(0.01)\end{array}$ \\
\hline $\begin{array}{c}-0.03 \\
(0.01)\end{array}$ & $\begin{array}{c}0.01 \\
(0.01)\end{array}$ & $\begin{array}{c}0.02 \\
(0.05)\end{array}$ & $\begin{array}{c}-0.11 \\
(0.05)\end{array}$ \\
\hline $\begin{array}{l}0.05 \\
(0.02)\end{array}$ & $\begin{array}{l}0.08 \\
(0.02)\end{array}$ & $\begin{array}{c}-0.06 \\
(0.01)\end{array}$ & $\begin{array}{c}-0.31 \\
(0.12)\end{array}$ \\
\hline
\end{tabular}

Notes. These parameters refer to the parameter estimates of the adjustment matrix that appears in the MS-VECM specification

$$
\Delta x_{t}=\mu_{s_{t}}+\alpha_{s_{t}} z_{t-1}+\pi_{s_{t}}(L) \Delta x_{t-1}+\epsilon_{t} .
$$

Standard errors are in parentheses. 
Figure 1. Evolution of equilibrium errors.
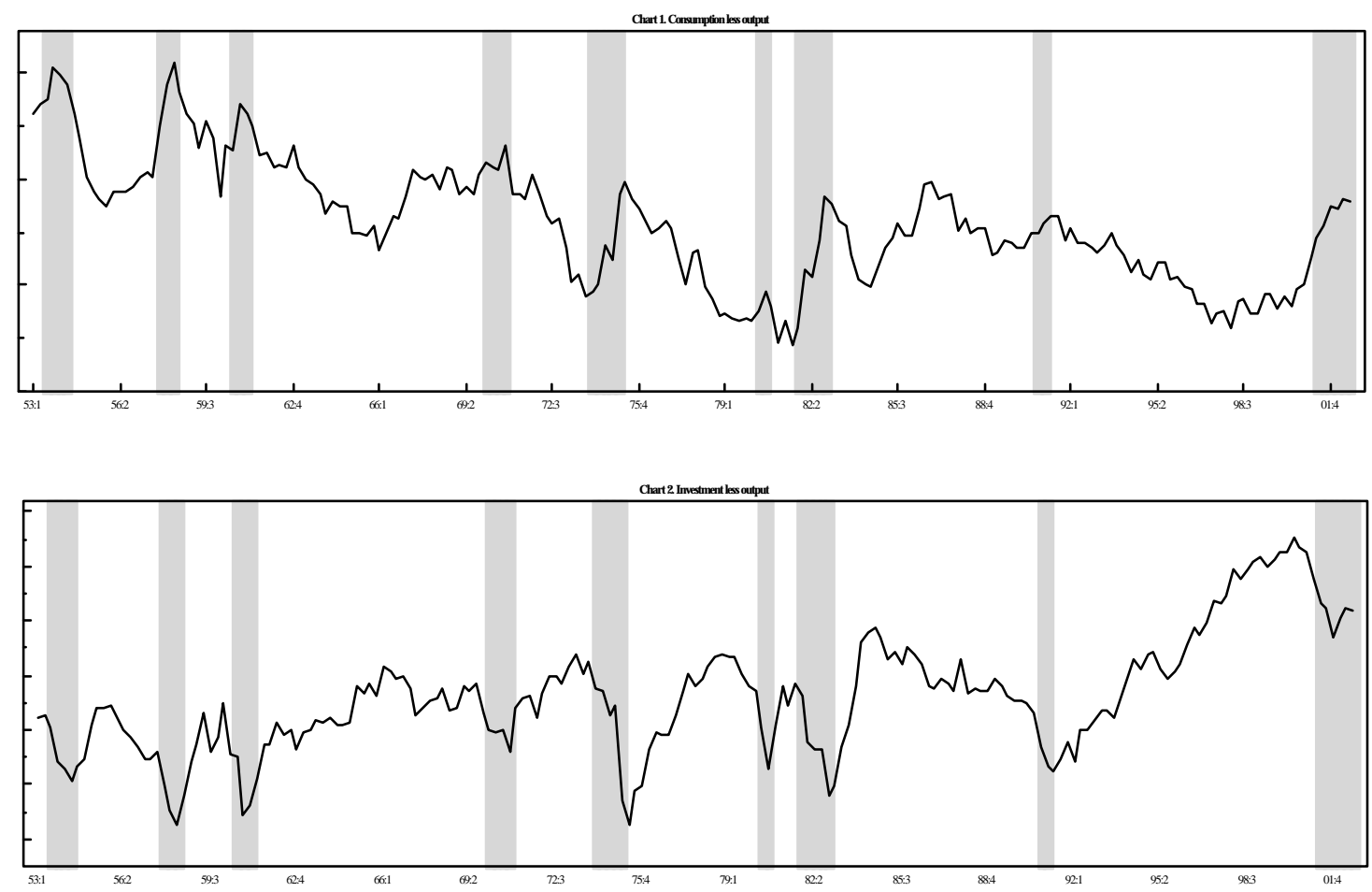

Notes. Logarithms of the consumption:output (Chart 1) and investment:output (Chart 2) ratios. To facilitate graphing, constants were added. Shaded areas are NBER recessions.

Figure 2. Filtered probabilities of recession.

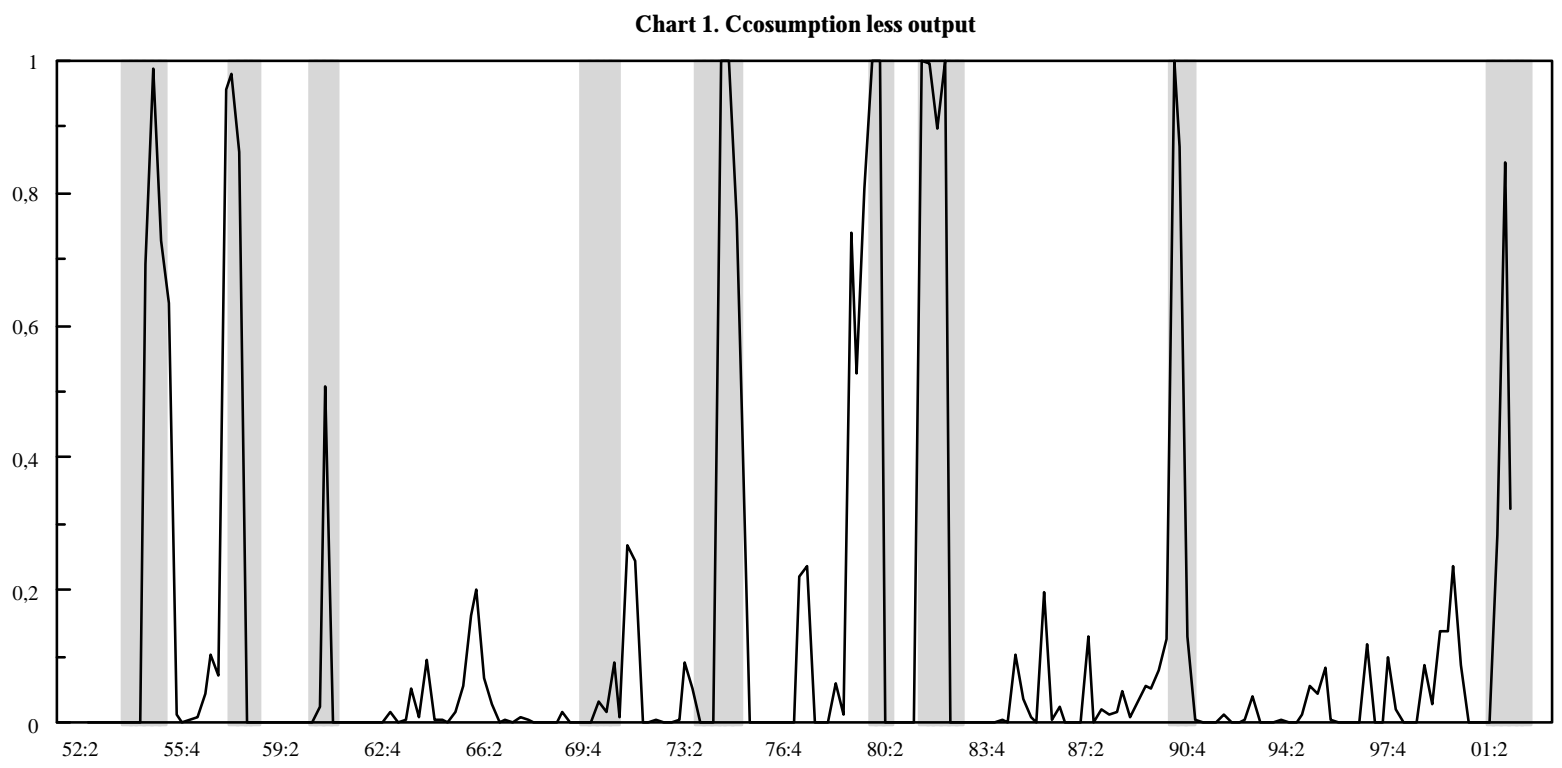

Notes: Smoothed probabilities of recession from a Markov-switching VAR for logarithms of the consumption:output (c-y) and investment:output (i-y) ratios. Shaded areas are NBER recessions. 
Figure 3. Evolution of output, consumption and investment

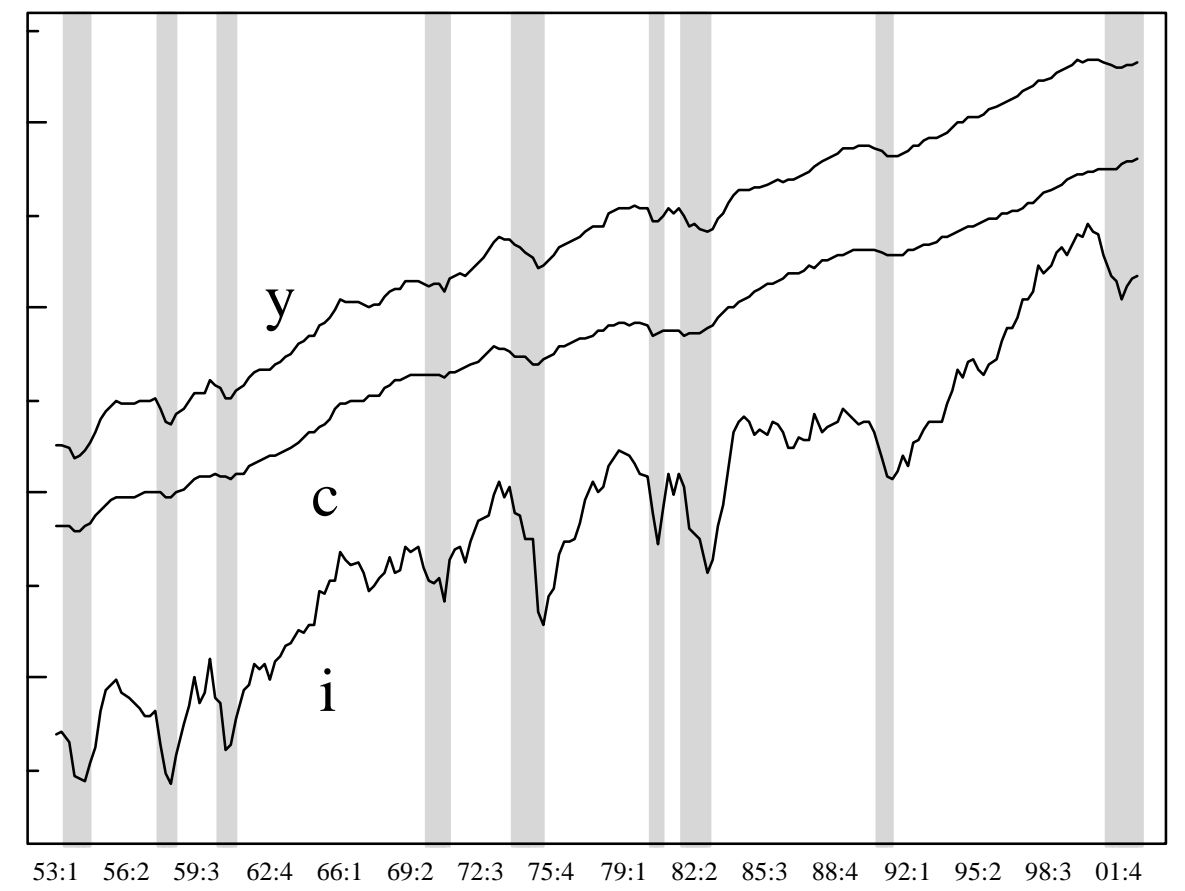

Notes. Logarithms of private output (y), consumption (c) and investment (y). To facilitate graphing, constants were added. Shaded areas are NBER recessions.

Figure 4. Filtered probabilities of recession.

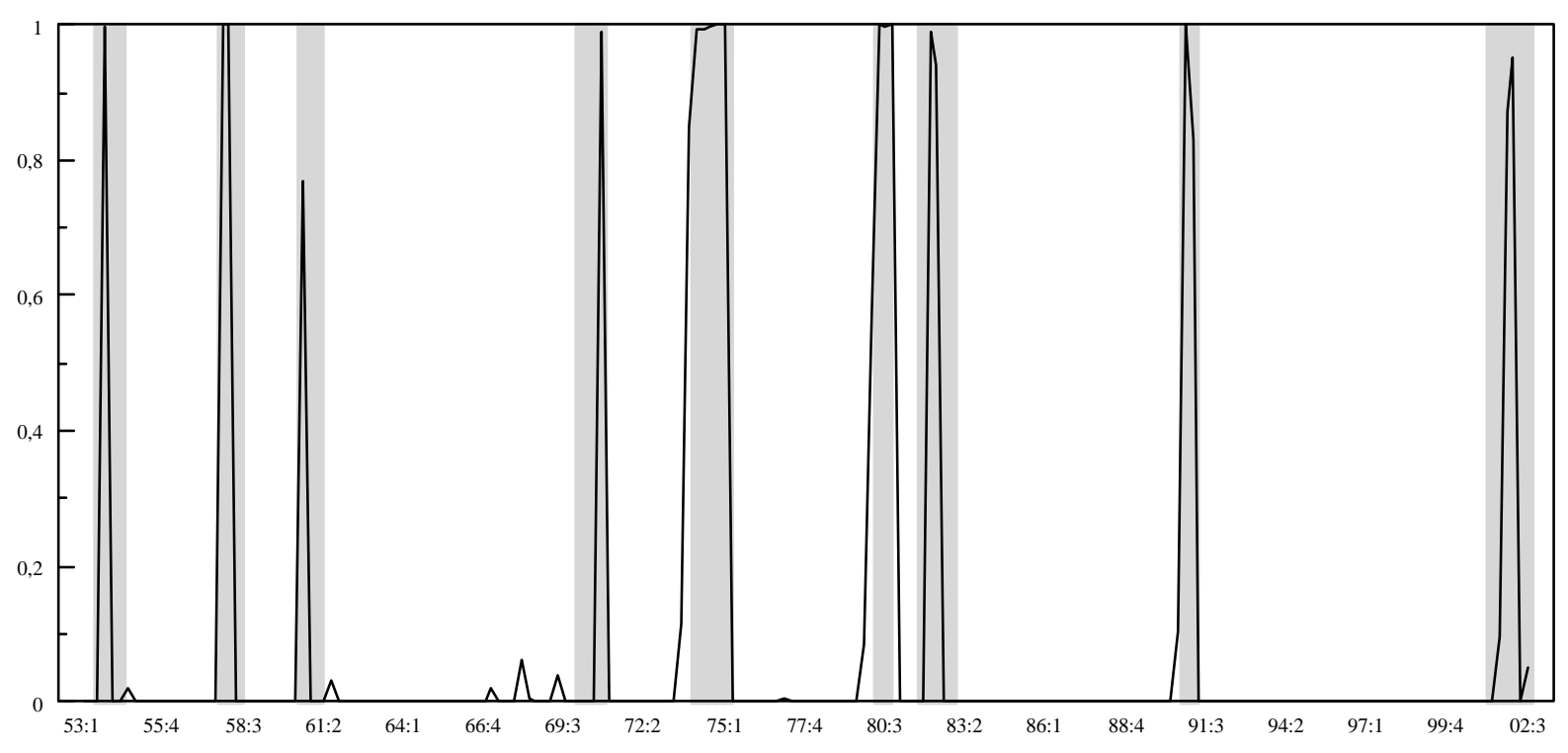

Notes. Filtered probabilites of recession from the Markov-switching common stochastic trends model. Shaded areas are NBER recessions. 
Figure 5. Backward-looking responses.

Panel 1. Backward response of y to permanent shocks

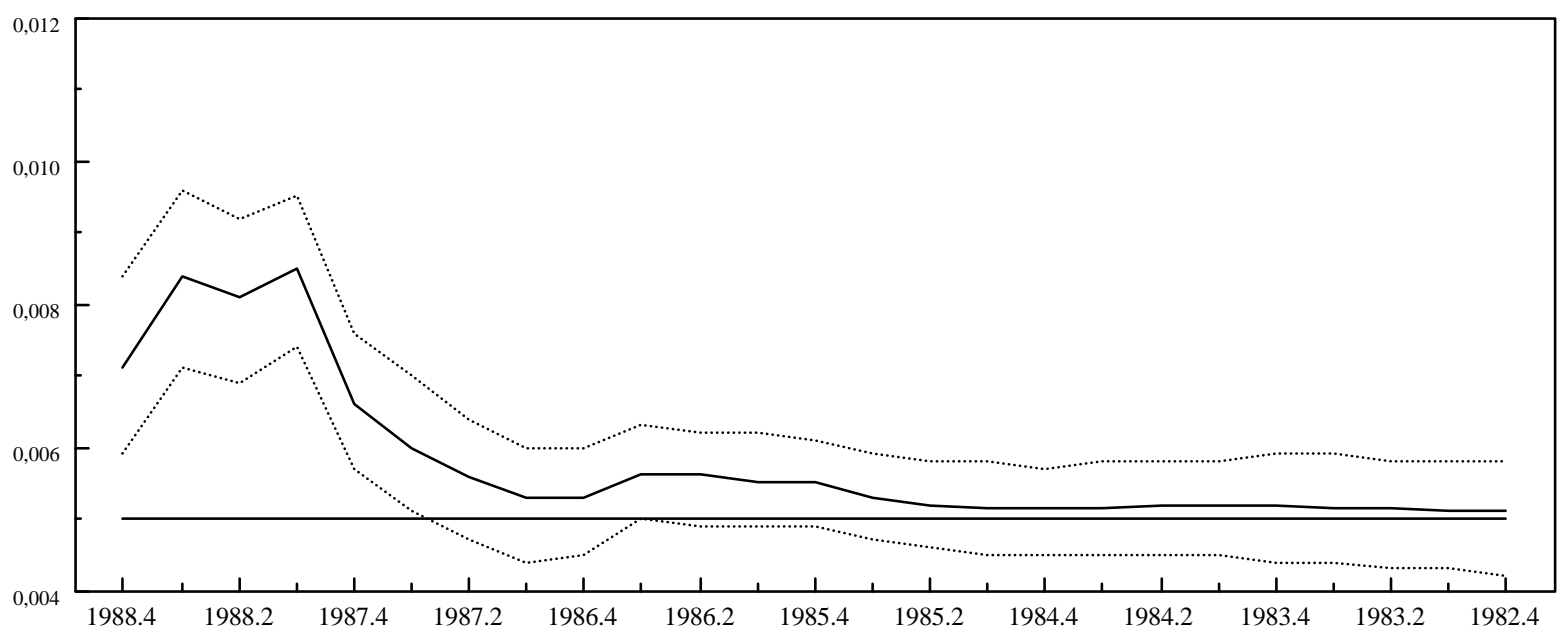

Panel 2. Backward response of $\mathrm{c}$ to permanent shocks

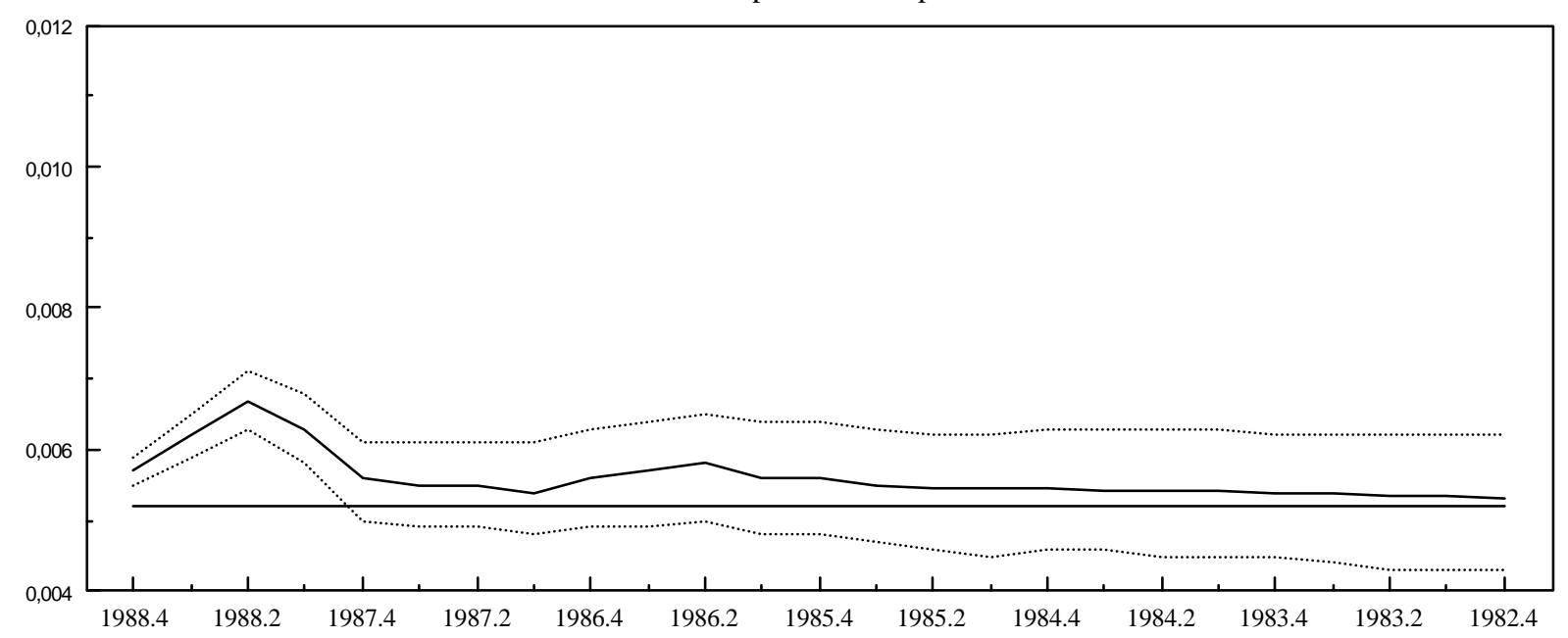

Panel 3. Backward response of $\mathrm{i}$ to permanent shocks

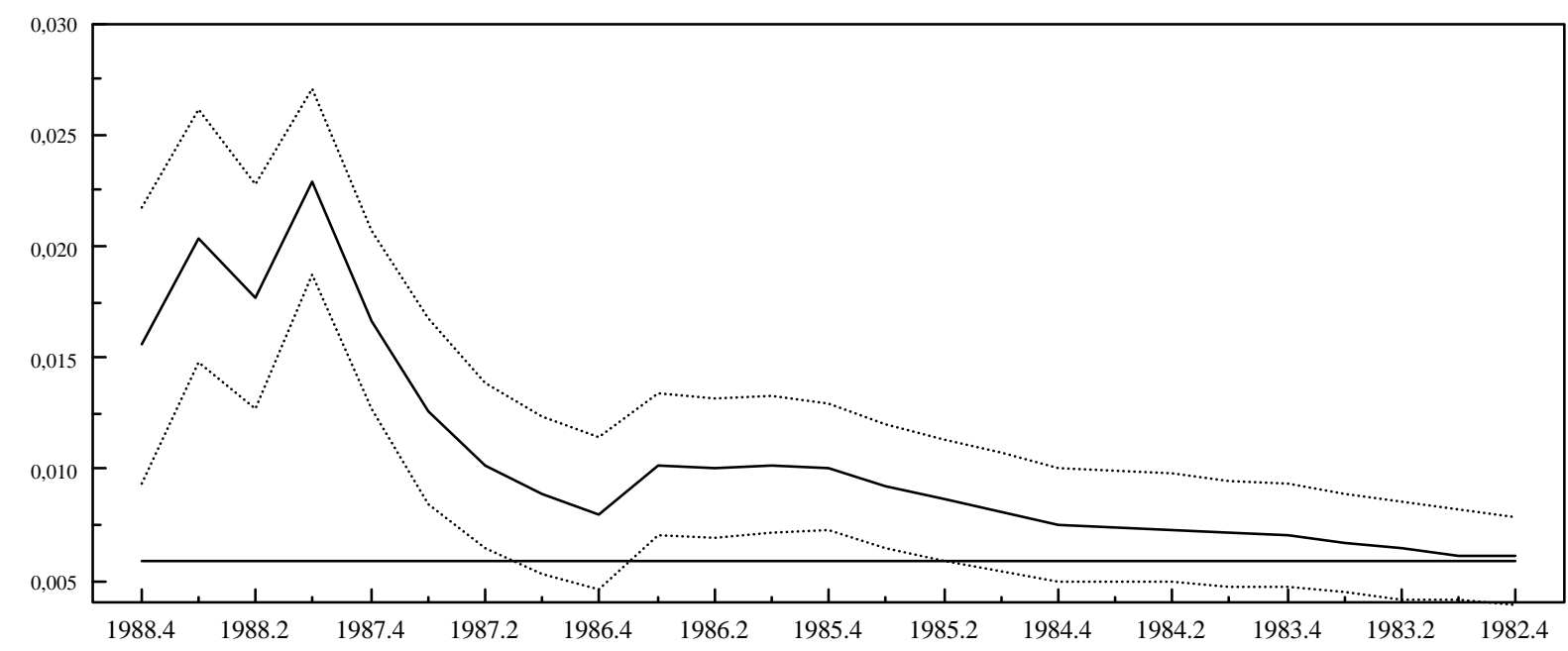

Notes. Backward-looking responses of output (Panel A), consumption (Panel B) and investment (Panel C) in 1988.4 to permanent shocks hitting the system in 1988.4-1982.4. Dashed lines are one-standard-deviation confidence bands computed by Monte Carlo simulations. Horizontal lines refer to the long-run responses. 
Figure 6.Markov-switching common stochastic trend.

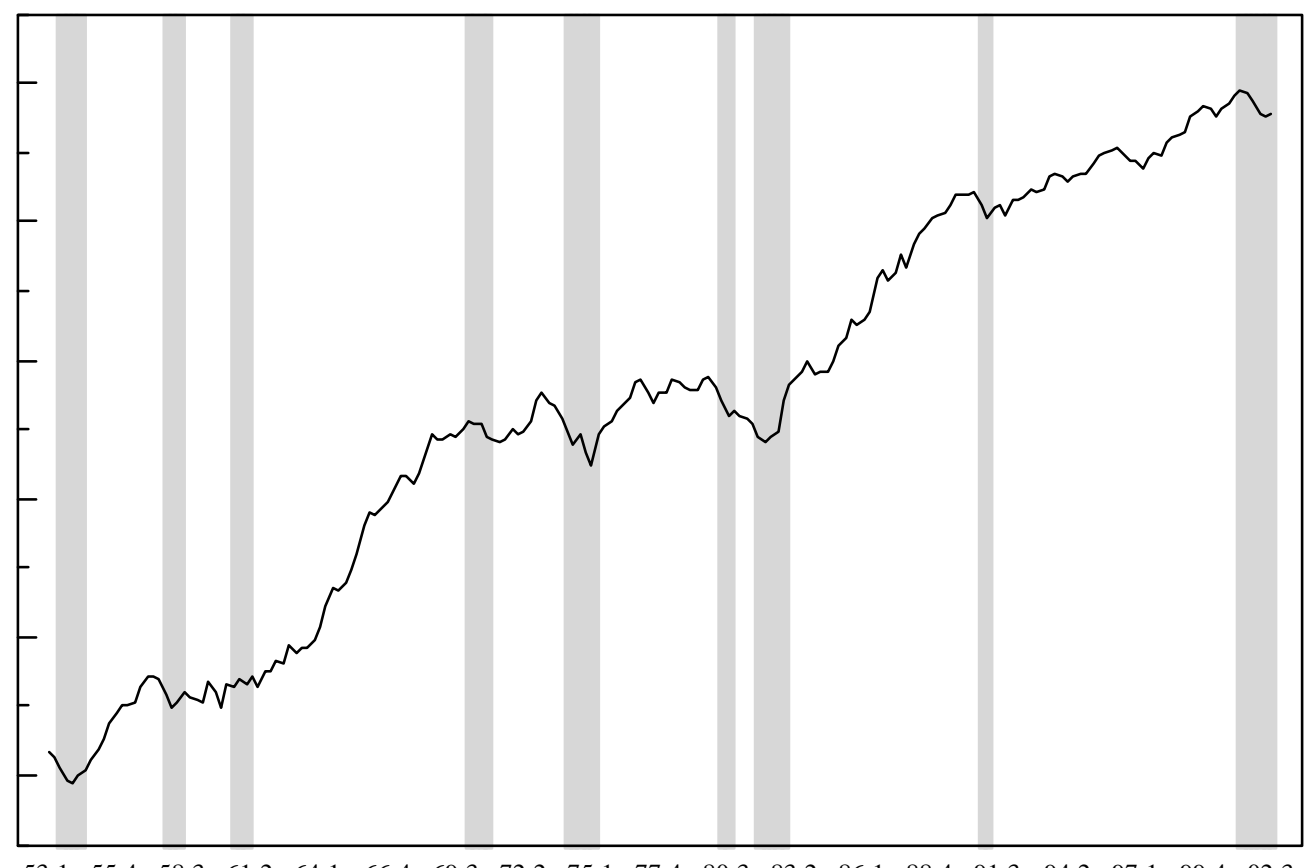

$\begin{array}{lllllllllllllllllll}53: 1 & 55: 4 & 58: 3 & 61: 2 & 64: 1 & 66: 4 & 69: 3 & 72: 2 & 75: 1 & 77: 4 & 80: 3 & 83: 2 & 86: 1 & 88: 4 & 91: 3 & 94: 2 & 97: 1 & 99: 4 & 02: 3\end{array}$

Notes. Shaded areas correspond to the NBER recessions. 